\title{
PROTECTED AREAS - DEVELOPMENT SUSTAINABILITY, ECONOMIC BENEFIT AND INTEGRATION OF LOCAL CULTURE IN GEORGIA
}

\section{MAIA AZMAIPARASHVILI}

\author{
Associate Professor, \\ European University, Georgia \\ maiaazmaiparashvili@gmail.com
}

\section{KEYWORDS: SUSTAINABLE TOURISM, ECOTOURISM, ECOLOGICAL SUSTAINABILITY RECREATIONAL RESOURCES, ECONOMICAL SUSTAINABILITY.}

For citation: Azmaiparashvili M. (2019), Protected Areas - Development Sustainability, Economic Benefit And Integration Of Local Culture In Georgia, Globalization And Business, №7, pp. 157-162. https://doi.org/10.35945/gb.2019.07.019

\section{INTRODUCTION}

Tourism is based on the goal-directed and clever using of tourist resources. Tourist resources are the subject of tourism, which have potential to satisfy the demands which occur in tourist process. Where there is no tourist resource, tourism cannot exist. Tourist resources are national property. Though the resources which have special meaning tourism gained worldwide significance.

Nowadays eco-tourism has become the most popular and fast developing industry. Eco-tourism means travelling to see the natural and manmade cultural variety without doing any harm to it. Eco-tourism is considered as one part of natural tourism, which joins together people, who travel with scientific - cognitive purpose. This tourists' interest is the environment, its observation, and partly its defending. In such kind of tourism the main interest is protected natural areas. According to this ecological tourism is considered as strictly specialized kind of brightly marked scientific-cognitive free time activity.

The development of tourism in Georgia underscores the existence of a network of national parks and other protected areas. With its natural landscapes it is known that protected areas now play an important role in protecting biodiversity, natural heritage of Georgia (and not only Georgia). In addition, protected areas are characterized by its unique natural-aesthetic characteristics. The purpose of the work is to study the example of protected areas, how the landscape diversity is perceived by the visitors and what role can be performed by the perceptual resources in the planning and management scheme of the Protected Areas. The paper also has an important place for visitors (statistics on the protected areas, survey of visitors s satisfaction, income from tourism and the sustainability of tourism sustainability on the quality of decadence.

The growth of demand on eco-tourism predetermined the necessity of founding protected areas and parks. Nowadays these areas represent the main objects of ecotourism. In the frame of especially defended natural area the organizers of eco-tourism prefer scientific-cognitive tourism, because they think that such eco-tours are easy to make. Some especially protected natural areas abroad which don't demand high qualification, let the participation of ecotourists. For example, a lot of eco-tourists are busy calculating the amount of biocenosis of different populations.

Ecotourism, to be successful, must promote sustainable development by establishing a durable productive base that allows local inhabitants and ecotourism service providers to enjoy rising standards of living. An ecotourism project must incorporate the social dimensions of productive organization and environmental conservation.

Tourism should develop sustainable, controlled and integrated basis. Using the principles of prudent planning. This concept provides a natural, cultural and other resources saving. Their continued use in the future so that they benefit society today. Tourism represents an important environmental protection enabled. Tourism is important to the protection of cultural heritage.

Sustainable development is concerned with acknowledging economic, social and environmental development 
aspects, catering for the current needs of society without damaging the well-being of future generations. Ecotourism is a niche market emerged because of increased market demands for sustainable tourism practices. It serves to provide tourism products and services which accommodating for the economic, social and environmental aspects of the society. However, earlier research suggests that it is difficult to handle the tree dimensions of sustainable development, indicating that trade-offs may occur. Furthermore, as tour operators are able to affect local development prospects, it is of interest to examine how they handle sustainable development, and more specifically, contribute to tradeoffs between, social and environmental pillars of sustainable development. (Eriksson, Lidstrom, 2013).

Ecotourism is a sub-component of the field of sustainable tourism. Ecotourism's perceived potential as an effective tool for sustainable development is the main reason why developing countries are now embracing it and including it in their economic development and conservation strategies. Ecotourism, as an alternative tourism, involves visiting natural areas in order to learn, to study, or to carry out activities environmentally friendly, that is, a tourism based on the nature experience, which enables the economic and social development of local communities. It focuses primarily on experiencing and learning about nature, its landscape, flora, fauna and their habitats, as well as cultural artifacts from the locality.

\section{STUDY AREA \& METHODS}

The understanding and recognition of significance of sustainable tourist achievements became the base of ecotourism. In the world of tourism the notion sustainable tourism and eco-tourism are used in the same way. Besides this close relation each of them has slight, but important special features. The conception of eco-tourism means more sympathy and duty from travelers. Sustainable tourism means the duty of the society to provide the protection and maintenance of the environment for the future generations. These conditions are not only political and economic factors and needs strengthening with the help of making decisions. We should realize what does ecologically sustainable environment means for the development of tourism and what part in this case plays eco-tourism as one of the main parts of the development of the sustainable tourism.(Charles Geldneri, JR Brent Ritchi, 2013).

The visitors opinion is very important for the protected areas and listening constructive criticism from them. We used data from visitor centers for our research. The quantitative and qualitative research methods are used. The target group and survey area were identified. Analyzed visitor statistics, visitor satisfaction survey, income and sustainability of tourism sustainability. Ensuring sustainability of sustainability, sustainable sustainability and development in the management of its management. Tourism innovative management is increasingly focused on managing local sustainability and its sustainability. Scholars do not argue that the destiny is the nucleus of tourism. Therefore, it is easy to evaluate the importance of sustainability, what practically resembles the sustainability of tourism. Nevertheless, less attention is paid to general destructions and, in particular, its sustainability problems.

In order to support safe management of tourism on the sites on the permanent bases, the monitoring is made according to the basic indicator of sustainable tourism. Here are used such indicators with the help of which the causeaffect connection between the tourism and the area is measured. The most important are two types of indicators: 1) the general indicator of sustainable tourism, which is worked out for general use in tourist sites. 2) the indicator of tourist site which is used with the particular eco-system or one of the tourist type.

In the second part of the 20th century because of the growth of tourism the mankind began to think more about difficult ecological situation in the world, in which tourism has already played its role. So in the process of developing of tourism it is important to take into consideration not only economical profit but also its ecological and social results, because the development of this branch won't be complete without its social economic and ecological.

It should be mentioned that the sustainable development of the areas which also belong to the eco-tourism sphere helps to develop tourism infrastructure, to create new working places, and to give work to the natives in the tourist service sphere, which naturally will rise people's level of ife in the region of the country.

For the sake of development of eco-tourism it has to be protected the variety of flora and fauna of the recreation regions and all natural resources. It is natural that eco-tourism won't be developed successfully if some amount of means taken from it aren't used for the protection of the recreation zones and for getting results from the recreation profit.

Unfortunately, nowadays the mankind is facing the global problem of secure of national resources, which main reason is modern way of life (principal oriented on consuming). As a result of irrational use of the national resources the natural may lose the resource of self-restoration, especially it refers to the forests, the degradation of which causes a lot of negative ecological results.

Georgia according to its geopolitical location and with its natural, historical or cultural resources has a lot of opportunities to develop tourism. Georgia represents the classical example of geographical landscape of vertical zones and has its almost complete variety from humid sub-tropics to zone. The most relevant regions to eco-tourism and health resorts are the regions, which are situated on Caucasian and South-Mtianeti's mountainous regions and on the Black Sea 
Coast. Along with aesthetic factor tourists are attracted by sea and mountainous medical features, the richest hydromineral resources.

\section{RESULTS \& DISCUSSIONS}

It must be mentioned that in the perspective of the development of eco-tourism, the international experts predict great future for Georgia. Along with other preferences they mention the geographical nearness of our country to the world's main tourist market - Europe.

Protection of nature is the strategic integral part of the development of eco-tourism. It can bring economical profit. This happens in eco-tourism when both the environment and business are healthy. Sometimes people's interests are sacrificed to the protection of the environment. For example the population maybe forbidden to perform agricultural works, to collect wood and building materials. The protection of nature is sacrificed to maximization of short -time profit, the existing eco-system is ruining. The degradation of tourist resources acts against both interests (protection of nature and eco-tourism.) It is important to understand that tourism can not develop without determined influence on the environment. It is impossible to make the main accent only on the development of tourism, without ecological care. One of the main principal of the sustainable development of eco-tourism is including the native people into it. Very often native people are excluded from this process artificially. (Gogelia, 2012).

The protection of natural, social and cultural resources and their sustainable usage is the base of long and successful activities. There are three main principles of sustainable development: ecological sustainability provides comparing of basic ecological processes with biological variety and biological resources; social and cultural sustainability predetermines such situations which provides people's control on their being along with material and cultural growth, which are concerned to this processes of development. Also helps to save local originality; economical sustainability provides effectiveness of economic development and such situation when future generations will use chosen methods of handling the operation of the resources. (Metreveli, 2012).

In tourism ecology and economy are more and more connected with the large system of causes and effects. Nowadays the mystery of popular tourist centers is based on the cleanliness of the environment. On the events of its effective defense and on the originality of the local culture in the places where there isn't any, it is noticed the decline of the level of service is noticed and also the shortage of volume of tourism. The aggravation of the environment, lots of cultural originality, the decline of economic situation. Local authorities are responsible for clever handling of the resources, so as future generation will have opportunities to use them.
So as to provide sustainable economy for tourism, tourist sustainability is needed. During the sustainable development of tourism the resources should be used so as to satisfy economic, social and esthetic needs, but at the same time maintain the originality of the country. The main biological variety of the environment and the main tourist systems, the stable development of tourism should provide social, cultural, ecological and economic criteria of harmonic mixture, which will give us not only maintenance of natural and cultural resources, but will become the predominance of their development and renovation.

The events of maintenance and protection of natural resources and cultural legacy have both global and local aspects. In order to make tourism sustainable, the character of tourist activities and capacity should foresee the existed natural and artificial resources throughput. The base of conception of tourism sustainable development is the concept of throughput potential. Throughput potential is the maximum loading which any tourist object can resist, without any serious harm to local resources, negative influence and social economic problems among the population (Birjakov, 2004).

The results of tourist statistics on protected areas are as follows: in 2018, the number of foreign visitors in the protected areas was 1108503 . As of 2018, most visitors visited Prometheus Cave - 185516 (19\%), Martvili Canyon 174,143 (136\%), Kazbegi National Park - 174,520 (17\%). Sataplia 81556 and Ottus 73 113. The number of visitors has increased to the following protected areas: Machakhela National Park - increase by $147 \%$, Martvili Canyon - increase by $136 \%$, Algeti National Park - increase by $74 \%$, Tbilisi National Park - $47 \%$ increase, Mtirala National Park - growth - $41 \%$, octane canyon - increase - $40 \%$, Prometheus cave increase - 19\%. Number of foreign visitors to Prometheus, Martvili, Chachuna, Mtirala and Tusheti Protected Areas exceeded the number of Georgian visitors. Visitor statistics by protected areas in 2019 (Source: Agency of Protected Areas. http://apa.gov.ge/en/s).

The growth of demand on eco-tourism predetermined the necessity of founding protected areas and parks. Nowadays these areas represent the main objects of ecotourism. In the frame of especially defended natural area the organizers of eco-tourism prefer scientific - cognitive tourism, because they think that such eco-tours are easy to make. Some especially protected natural areas abroad which don't demand high qualification, let the participation of ecotourists. For example, a lot of eco-tourists are busy calculating the amount of biocenosis of different populations.

Incomes received from tourism services of protected areas amounted to 4,504,473 lari, compared to the previous year $+94.7 \%$. Income of receiving income was: Prometheus Cave - GEL 1,887,064, Martvili Canyon - GEL 1,274,463, Oktes Canyon - 538,506 GEL and Sataplia - 499,019 GEL.

According to the information received from the Agency 
of Protected Areas of Georgia, $84 \%$ of visitors surveyed in the protected areas of Georgia and the service received during the summer are satisfied. Most of the visitors - $88 \%$ will definitely ask friends to visit Georgian Protected Areas. $68.8 \%$ of respondents assess the attitude of the personnel to the visitor very friendly. When traveling on protected areas, you feel protected by $88.3 \%$.

\section{CONCLUSIONS}

Sustainable development is the process of continuous changes, in the frame of which the using of resources, investment, technological progress and other innovations are developed according to the demands of future and present.

Conceptual question is, if it is reasonable to develop eco-tourism in strictly defended natural areas, the discussion topic till these days, both among scientific society and among the workers of these protected areas. The main argument is that the development of the protected areas happen the principals of the work of the preserves and nature, with the help of organized tourism and scientific expeditions, also to make excursions for servants, supporting the students' specifically, as an untouchable natural standard, on which only scientific research is made. On the territory of Georgia the main aim of preserves should be the following: to explain to the people practice and tourism.

Among the systems of the development of the preserves is such as: preserve is the protected area of natural processes and preserving the resources in genetic dynamic and untouched position and scientific research activities and monitor of the environment. This is the school of the nature protection and we shouldn't be afraid of people, but we should create such conditions that their presence in the preserves shouldn't become the violation of the conditions of being in the preserve.

The development of eco-tourism of the protected areas is the important question which influences the economic situations of the regions, it also can activate the protection of nature in the country. To our mind strictly protective natural areas can not only strengthen ecological tourism in the country, but also give a stimuli to the tourists to come to the territory of Georgia. The natural areas which are protected for this reasons have uniquely organized territory, have professional scientific and administrative person, the practice of protecting and restoration of ecological systems, close contacts with national fundamental science, the opportunity of sharing the experience of working abroad, have protected structures. The participants of eco-tourism should develop such service and offers which will correspond to the demands of tourist market, which will become a guarantee of attraction of tourists. The government should play the great part in this with its supportive policy, which involves the developing of infrastructure, the search of different educational programs and inves- tors. In this direction the last aim of the government is the development of financially profitable industry of eco-tourism in the conditions of protecting and improving the nature. It is important for tourist experts to take an active part in the planning process of natural parks and protected areas. It is important for tourist specialists and the administration of protected areas to work together in the sphere of planning the tours and administration.(Bliadze, Bordzikuli, 1998).

Georgia is rich in recreational resources. Georgia can become one of the powerful centers of the world tourism. A thorough study of the forests we see climates-recreational functions, mineral and thermal springs medicinal properties, grotto, spa resorts and places of functions, we come to the conclusion, that along with the tourism Georgia may become a health cache. Nature has richly rewarded Georgia with tourist recreational resources. The world is not found in such places, where a small area, which our country has, there are so many different landscapes. That's why Georgia for its unique natural-gives economic conditions-one of the strong possibility of becoming a tourist country. Are only a few countries in the world, which is natural - climate and recreation - spa resources, so of the God "rewarded".

It is impossible not to note, that tourism development that gives a sense of national pride, because your country, its nature and culture becomes recognizable. Tourism can be considered as the best means of communication to the world. Each of them tells a lot about his journey, thus evokes a desire for others to see it.

There is no doubt that tourism can not be developed in the country without the system of protected areas. The existence of tourism depends on the functionality of ecosystems and services offered by them. of the enormous potential of tourism development, because it has a variety of natural areas, aesthetically attractive landscapes, urbanization and gakulturebis processes intact the unique flora and fauna, and international endangered species included in the not so little amount of relict and endemic species, natural areas and ax and has developed networks. The ecotourists make the country a special attraction for the wealth of ethno-cultural, the diversity of public holidays, customs, traditional hospitality of the population.

One of the most important conditions for the ecological and tourism activities is to provide rational, sustainable nature of use in protected areas. Tourism and environmental conditions are interconnected. The environment contains a lot of elements. The most important factor in achieving sustainable development is development and management of tourism that will not harm the environment. The provision of sustainability, maintenance and development is driven by its management. The essence and sustainability of sustainable management is that it does not violate the balance of destiny, the sustainability of deserting is ensured in all three directions: environment, economy, socio-cultural heritage. 


\section{REFERENCES:}

1. Eriksson F., Lidstrom M. (2013). Sustainable development in ecotourism, Umeå Umeå School of Business and Economics, pp 34-38

2. Charles Geldneri R., JR Brent Ritchi (2013). Tourism -Basics - practice - theory, publishing “ Batumi Shota Rustaveli State University « pp 432-443;

3. Gogelia M. (2012). Ecotourism and its development prospects», Akaki Tsereteli State University, International Scientific Conference Proceedings, innovative technologies and modern materials, pp. 67-89.

4. Metreveli, M. (2012). Environment and Ecotourism Management, Publisher "forma", pp 51-62

5. Birjakov, M. (2004). Tourism Theories - 2nd Edition, "fotoni", pp 44-60

6. Bliadze - Bordzikuli M. (1998). recreational resources of Georgia. Strategic Research and Development Center of Georgia, pp 25-30

7. Qiqodze A., Goxelashvili R. (2007). Protected Areas of Georgia. Department of Protected Areas.

8. www.gccw.org

9. https://journals.gisap.eu/

10.http://drg.com.ge/team.php

11. http://apa.gov.ge/en/statistika/vizitorta-statistika/visitorOstatistics-by-protected-areas-in-2019

12. http://greenalt.org/wp-content/uploads/2018/07/biodiversity_monitoring_2018.pdf

13. www.geostat.ge 


\section{PROTECTED AREAS - DEVELOPMENT SUSTAINABILITY, ECONOMIC BENEFIT AND INTEGRATION OF LOCAL CULTURE IN GEORGIA}

\section{MAIA AZMAIPARASHVILI}

Associate Professor,

European University, Georgia

maiaazmaiparashvili@gmail.com

\section{KEYWORDS: SUSTAINABLE TOURISM, ECOTOURISM, ECOLOGICAL SUSTAINABILITY,} RECREATIONAL RESOURCES, ECONOMICAL SUSTAINABILITY.

For citation: Azmaiparashvili M. (2019), Protected Areas - Development Sustainability, Economic Benefit And Integration Of Local Culture In Georgia, Globalization And Business, №7, pp. 157-162. https://doi.org/10.35945/gb.2019.07.019

\section{SUMMARY}

Tourism is based on deliberate and reasonable consumption of tourist resources. The object of research is Ecological Tourism, Protected Areas - Development Sustainability, Economic Benefit and Integration of Local Culture in Georgia. The understanding and recognition of significance of sustainable tourist achievements became the base of eco-tourism. In the world of tourism the notion sustainable tourism and eco-tourism are used in the same way. Besides this close relation each of them has slight, but important special features. Sustainable tourism means the duty of the society to provide the protection and maintenance of the environment for the future generations. These conditions are not only political and economic factors and needs strengthening with the help of making decisions.
We should realize what does ecologically sustainable environment means for the development of tourism and what part in this case plays eco-tourism as one of the main parts of the development of the sustainable tourism.

With its natural landscapes it is known that protected areas now play an important role in protecting Georgiass biodiversity, natural heritage. In the work there is a significant place for visitors (statistics on the protected areas, survey of visitors) satisfaction, income from tourism and the sustainability of tourism sustainability. So as to provide sustainable economy for tourism, tourist sustainability is needed. During the sustainable development of tourism the resources should be used so as to satisfy economic, social and esthetic needs, but at the same time maintain the originality of the country. 